\title{
Analysis of the Surveying Errors in the Cabanasses Ramp Breakthrough
}

\author{
Lluís Sanmiquel ${ }^{1}$, Marc Bascompta ${ }^{1}$, Hernán Anticoi ${ }^{2}$, Nor Sidki ${ }^{1}$ \\ ${ }^{1}$ Department of Mining Engineering, Industrial and ICT. \\ Polytechnic University of Catalonia (UPC), Avenue Bases de Manresa, 61-73, 08242-Manresa Spain \\ lluis.sanmiquel@upc.edu; marc.bascompta@upc.edu; nor.sidki@upc.edu \\ ${ }^{2}$ Department of transportation and process project technology. \\ Polytechnic School of Mines and Energy (UNICAN) Boulevard Ronda Rufino Peón 254, 39316-Torrelavega Spain \\ anticoihf@unican.es
}

\section{Extended Abstract}

The Cabanasses Ramp is a complex tunnel designed to access the Cabanasses Mine and improve the environmental conditions, safety and production capacity. Its construction started in July 2012, finishing in 2020. Until now, the only access to the Mine was through 2 mine shafts called "Pozo 2" and "Pozo 3".

The Cabanasses Mine is located in Súria (Bages, Catalonia, Spain). The Ramp will be about $5.1 \mathrm{~km}$ length, descending more than $800 \mathrm{~m}$ with a high gradient, with a maximum slope of $21 \%$. One the first surveying works carried out during the construction of this ramp was the transmission of the orientation and cartographic system, between surface and underground workings, by means of the vertical shafts. In the study [1], it was assessed the accuracy of this operation in a case study using the two-shaft plumbing and gyroscopic methods in order to compare and analyze the planimetric displacement of the baseline due to different sources of error in each method.

The second group of topographic works were the planimetric and altimetric polygonal surveys that were carried out in the mine branch and the advance branch from the outside. It is important to note that from the mine branch, only $0.5 \mathrm{~km}$ were excavated, while the rest of the ramp, $4.6 \mathrm{~km}$, was excavated from the outside branch. The ramp in the mine started near the INT11N-INT10N base located about $3 \mathrm{~km}$ from the entrance shafts, and about $600 \mathrm{~m}$ from the breakthrough (meeting point of the ramp between the outside branch and the mine branch). It is well known that some errors are always found in the planimetric and altimetric polygonal surveys. In fact, several studies indicate that these errors are due to the propagation of errors in the measurement of angles and distances at each station of the polygonal [2,3]. Moreover, these errors, especially those related to planimetric orientation, accumulate as the polygonal is progressing.

In short, there was the need to carry out two closed polygonal underground chains, one along the outside branch and the other one in the inner branch to achieve the breakthrough from both sides. Several gyroscopic observations were required to verify and control the accuracy of the topographic results obtained. The usage of a gyroscope survey is a method widely used in the transmission of the orientations to underground works [4]. This information is crucial to avoid the effect of lateral refraction and all the errors that can be generally accumulated in underground surveying.

The surveys done for the breakthrough were validated on the $21^{\text {th }}$ of December 2021, when the connection from both sides was done. Obtaining the following errors: X: $-0.004 \mathrm{~m}$; Y: $-0.034 \mathrm{~m}$; Z: $-0.033 \mathrm{~m}$. Achieving an accuracy substantially higher than the expected values, either planimetry or altimetry.

\section{References}

[1] L. Sanmiquel, M. Bascompta, J.M. Rossell, “Assessment of errors in the transmission of the orientation and cartographic system from the surface to an underground mine," Journal of the Southern African Institute of Mining and Metallurgy, vol. 120, no. 2, pp. 139-148, 2020.

[2] R. David, F. Foote, J. Anderson, E. Mikhail, "Surveying. Theory and Practice (sixth ed.)," McGraw-Hill, 1981.

[3] S.C. Stiros, "Alignment and breakthrough errors in tunnelling," Tunnelling and Underground Space Technology, vol. 24, pp. 236-244, 2009.

[4] N. Benecke, U. Kalz, "Ensuring tunnel navigation by cost-effective gyroscope control measurements," Tunnelling and Underground Space Technology, vol. 24, pp. 236-244, 2009. 